\title{
Trauma Surgery $\&$ Acute Care Open \\ Impact of shelter-in-place order for COVID-19 on trauma activations: Santa Clara County, California, March 2020
}

\author{
Joseph D Forrester, ${ }^{1}$ Raymond Liou, ${ }^{1}$ Lisa M Knowlton, ${ }^{1}$ Ronald M Jou, ${ }^{2}$ David A Spain ${ }^{1}$
}

'Department of Surgery, Stanford University, Stanford, California, USA

2Department of Surgery, Santa Clara Valley Medical Center, San Jose, California, USA

Correspondence to Dr Joseph D Forrester; jdf1@ stanford.edu

Received 30 April 2020 Accepted 1 May 2020 (c) Author(s) (or their employer(s)) 2020. Re-use permitted under CC BY-NC. No commercial re-use. See rights and permissions. Published by BMJ.

To cite: Forrester JD, Liou $R_{\text {, }}$ Knowlton LM, et al. Trauma Surg Acute Care Open 2020:5:e000505.

\section{ABSTRACT}

Introduction The shelter-in-place order for Santa Clara County, California on 16 March was the first of its kind in the USA. It was unknown what impact this order would have on trauma activations.

Methods We performed a retrospective analysis of institutional trauma registries among the two American College of Surgeons Level 1 trauma centers serving Santa Clara County, California. Trauma activation volumes at the trauma centers from January to March 2020 were compared with month-matched historical cohorts from 2018 to 2019.

Results Only 81 (3\%) patients were trauma activations at the trauma centers in the 15 days after the shelterin-place order went into effect on 16 March 2020, compared with 389 activations during the same time period in 2018 and $2019(p<0.0001)$. There were no other statistically significant changes to the epidemiology of trauma activations. Only one trauma activation had a positive COVID-19 test.

Discussion Overall trauma activations decreased 4.8fold after the shelter-in-place order went into effect in Santa Clara County on 16 March 2020, with no other effect on the epidemiology of persons presenting after traumatic injury.

Conclusion Shelter-in-place orders may reduce strain on healthcare systems by diminishing hospital admissions from trauma, in addition to reducing virus transmission.

\section{INTRODUCTION}

The novel corona virus, severe acute respiratory syndrome coronavirus 2 (COVID-19), was identified in December 2019 in Wuhan, China. ${ }^{1}$ The first cases of COVID-19 were reported in Santa Clara County, California, on 31 January and 2 February $2020 .^{2}$ Over concern for community transmission of COVID-19, on 16 March 2020 the Santa Clara County Public Health Department issued a shelterin-place order to improve social distancing. ${ }^{3}$ There are two verified Level 1 trauma centers that provide trauma care to $70 \%-80 \%$ of the 1.938 million residents of Santa Clara County, and it was not known how this proactive public health intervention would impact trauma volume. Our objective to was assess how the shelter-in-place order would impact trauma activation volume at our two centers.

\section{METHODS}

We compared trauma activation volumes at the trauma centers from January to March 2020 to month-matched historical cohorts of trauma activations from 2018 to 2019. Patients were identified using institutional trauma registries. Epidemiologic variables assessed included age, sex, admission to the hospital or an intensive care unit (ICU), injury severity score (ISS) and mechanism of injury. Minor and major trauma activations were grouped according to pre-existing trauma center-specific definitions. Patients were considered positive for alcohol if they had a blood alcohol level $\geq 0.08$. Any drug identified on urine toxicology screen not administered during initial trauma assessment was considered a positive. Missing values were not included in the analysis, and variables with missing values are reported as such. Fisher's exact and Wilcoxon rank sum test were used to compare categorical and numerical variables respectively. $\mathrm{P}<0.05$ was considered significant. This study was exempted by the Institutional Review Boards of both institutions.

\section{RESULTS}

Between January and March 2018, 2019 and 2020, there were a total of 3057 trauma activations. There were 1170 (38\%) activations in 2018, 974 (32\%) activations in 2019 and 913 (30\%) activations in 2020. Median age was 38 (range: $<1-103$ ) years and $1995(65 \%)$ were male. Two thousand five hundred and seventy-five (84\%) activations were minor traumas and $482(16 \%)$ were major traumas. Nine hundred and sixty (31\%) activations occurred on the weekend. There were 397 (19\%) patients positive for alcohol and 226 (11\%) positive for drugs, among patients with this information available. Median ISS was 5 (range: 1-75). Blunt mechanisms were reported for most trauma activations $(n=2866,94 \%)$. A total of $1523(50 \%)$ trauma activations required admission to the hospital. Of these, 484 (16\% of all activations) resulted in ICU admissions. There were $11(0.4 \%)$ patients who died in the trauma bay.

Only $81(3 \%)$ patients were trauma activations at the trauma centers in the 15 days after the shelter-in-place order went into effect on $16 \mathrm{March}$ 2020, compared with 389 activations during the same time period in 2018 and 2019 (p<0.0001) (figure 1). While fewer patients were admitted on weekend days after the shelter-in-place order went into effect ( $14 \%$ vs $31 \%, \mathrm{p}<0.0001)$, there were no other statistically significant changes to the epidemiology of trauma activations. Only one trauma activation had a positive COVID-19 test. 


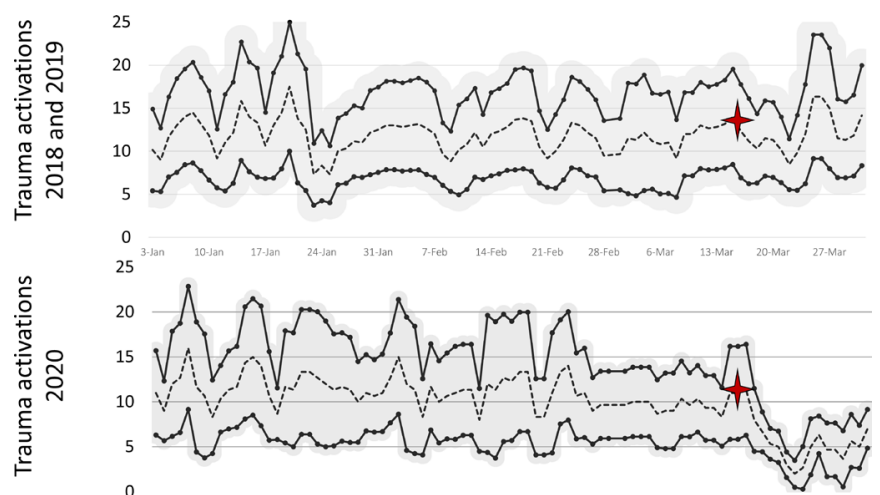

Figure 1 Trauma activations in Santa Clara County, California January-March, 2018-2020. Upper graph represents trauma activations during 2018 and 2019. Lower graph represents trauma activations in 2020. Dotted line is 3-day running average with the upper and lower bounds of the SD with solid lines. Cardinal star marks 16 March.

\section{DISCUSSION}

Overall trauma activations decreased 4.8-fold after the shelter-inplace order went into effect in Santa Clara County on 16 March 2020. There was otherwise no change to the epidemiology of the traumatically injured patients presenting to these two institutions. To our knowledge, no trauma-specific assessments have occurred with prior infectious disease outbreaks where quarantine or shelter-in-place order was enforced. However, with both the severe acute respiratory syndrome outbreak in 2003 and the Ebola virus disease outbreak in West Africa in 2014 and 2015, similar drops in inpatient hospital admissions were identified. ${ }^{56}$ While the observed decrease in trauma activations inherently makes sense as there are fewer motor vehicles in use, the impact on interpersonal violence and mental health is not as clear. ${ }^{7}$ It is important to note, therefore, that our two centers have a high frequency of blunt traumatic injury; the reduction in trauma activations we observed may not be reflective of the experience in other locales, particularly those in large metropolitan areas with higher frequencies of penetrating trauma.

\section{CONCLUSION}

Shelter-in-place orders may help reduce the strain on healthcare systems by diminishing hospital admissions from trauma, in addition to reducing virus transmission. Further longitudinal research is needed to assess if the decrease in number of trauma activations remain sustained over time.

Contributors JDF: data acquisition, manuscript preparation and editing; RL and RMJ: data acquisition and manuscript preparation; LMK and DS: manuscript preparation and editing.

Funding The authors have not declared a specific grant for this research from any funding agency in the public, commercial or not-for-profit sectors.

Competing interests None declared.

Patient consent for publication Not required.

Provenance and peer review Not commissioned; internally peer reviewed.

Open access This is an open access article distributed in accordance with the Creative Commons Attribution Non Commercial (CC BY-NC 4.0) license, which permits others to distribute, remix, adapt, build upon this work non-commercially, and license their derivative works on different terms, provided the original work is properly cited, appropriate credit is given, any changes made indicated, and the use is non-commercial. See: http://creativecommons.org/licenses/by-nc/4.0/.

\section{REFERENCES}

1 Huang C, Wang Y, Li X, Ren L, Zhao J, Hu Y, Zhang L, Fan G, Xu J, Gu X, et al. Clinical features of patients infected with 2019 novel coronavirus in Wuhan, China. Lancet 2020;395:497-506.

2 Cody SH. Letter from the Health Officer - February 3, 2020: Santa Clara County Department of Public Health, 2020.

3 Zwald ML, Lin W, Sondermeyer Cooksey GL, Weiss C, Suarez A, Fischer M, Bonin BJ, Jain S, Langley GE, Park BJ, et al. Rapid Sentinel Surveillance for COVID-19 - Santa Clara County, California, March 2020. MMWR Morb Mortal Wkly Rep 2020;69:419-21.

4 Cody SH. Order of the health officer of the County of Santa Clara: Santa Clara County Department of Public Health, 2020.

5 Schull MJ, Stukel TA, Vermeulen MJ, Zwarenstein M, Alter DA, Manuel DG, Guttmann A, Laupacis A, Schwartz B. Effect of widespread restrictions on the use of hospital services during an outbreak of severe acute respiratory syndrome. CMAJ 2007;176:1827-32.

6 Bolkan HA, van Duinen A, Samai M, Bash-Taqi DA, Gassama I, Waalewijn B, Wibe $A$, von Schreeb J. Admissions and surgery as indicators of hospital functions in Sierra Leone during the west-African Ebola outbreak. BMC Health Serv Res 2018;18:846

7 Dailey SF, Kaplan D. Shelter-in-place and mental health: an analogue study of wellbeing and distress. J Emerg Manag 2014;12:121-31. 